\title{
Erratum to: Characterization and manipulation of fruit susceptibility to Drosophila suzukii
}

\author{
Jana C. Lee ${ }^{1}$ Daniel T. Dalton ${ }^{2} \cdot$ Katharine A. Swoboda-Bhattarai $^{3}$ \\ Denny J. Bruck ${ }^{1,4} \cdot$ Hannah J. Burrack ${ }^{3}$ Bernadine C. Strik ${ }^{2}$. \\ J. Megan Woltz ${ }^{1,2} \cdot$ Vaughn M. Walton ${ }^{2}$
}

Published online: 7 January 2016

(c) Springer-Verlag Berlin Heidelberg 2016

\section{Erratum to: J Pest Sci \\ DOI 10.1007/s10340-015-0692-9}

Unfortunately, there is an error in the Table 3 in the original publication of the article.

The coating "Calcium silicate" has a product name of "Mainstay Calcium Si," not "Mainstay Calcium". The corrected Table 3 is shown below.

The online version of the original article can be found under doi:10.1007/s10340-015-0692-9.

Jana C. Lee

jana.lee@ars.usda.gov

1 USDA-ARS Horticultural Crops Research Unit, 3420 NW Orchard Ave., Corvallis, OR 97330, USA

2 Department of Horticulture, Oregon State University, 4017 Ag and Life Sciences Bldg., Corvallis, OR 97331, USA

3 Department of Entomology, North Carolina State University, Campus Box 7630, Raleigh, NC 27695, USA

4 Present Address: DuPont Pioneer, 7300 NW 62nd Ave., Johnston, IA 50131, USA 
Table 3 Coatings sprayed on blueberry plants during fruit development (from immediately after fruit set through early blue stage) in a mature field near Salem, Oregon, US

\begin{tabular}{|c|c|c|c|c|}
\hline Coating & Spray dates & Rate & $\mathrm{L} / \mathrm{ha}$ & Product information \\
\hline Chelated calcium & $\begin{array}{l}\text { 23, } 30 \text { April, 8, 14, } 31 \text { May, 7, 15, } \\
\text { 22, } 27 \text { June, } 4 \text { July } 2013\end{array}$ & $1.5 \%$ by volume & 16 & $\begin{array}{l}\text { Biomin }^{\circledR}, \text { JH Biotech, Inc., } \\
\text { Ventura, CA }\end{array}$ \\
\hline Calcium borate & $\begin{array}{l}\text { 23, } 30 \text { April, 8, 14, } 31 \text { May, 7, 15, } \\
\text { 22, } 27 \text { June, } 4 \text { July } 2013\end{array}$ & $1.5 \%$ by volume & 16 & $\begin{array}{l}\text { Phyta-Set } \mathrm{QC}^{\mathrm{TM}} \text {, California } \\
\text { Organic Fertilizers, Inc., } \\
\text { Hanford, CA }\end{array}$ \\
\hline Calcium silicate & $\begin{array}{l}30 \text { April, 8, 14, } 31 \text { May, 7, 15, 22, } \\
27 \text { June, } 4 \text { July } 2013\end{array}$ & $1.1 \%$ by volume & 12 & $\begin{array}{l}\text { Mainstay Calcium Si, Redox } \\
\text { Chemicals, LLC, Burley, ID }\end{array}$ \\
\hline Gibberellic acid (GA3) & 15 June 2013 & $30 \mathrm{ppm}$ & 0.03 & $\begin{array}{l}\text { ProGibb }^{\circledR} \text { Plus } 2 \mathrm{X} \text {, Valent } \\
\text { BioSciences Corporation, } \\
\text { Libertyville, IL }\end{array}$ \\
\hline Biofilm & 8, 31 May, 15, 27 June 2013 & $0.5 \%$ by volume & 5.4 & Parka $^{\mathrm{TM}}$, Cultiva, Portland, OR \\
\hline
\end{tabular}

Fruit were used in a laboratory assay for oviposition by $D$. suzukii 